\title{
Mujer y trabajo al margen
}

\section{Woman and work at margin}

José Delgado Ruiz

Abogado

Doctor en Derecho. Universidad Carlos III de Madrid

ORCID: 0000-0002-2536-4906

Recibido: $23 / 10 / 2019$

Aceptado: 23/12/2019

doi: https://doi.org/10.20318/femeris.2020.5388

Resumen. Transitar por los laberintos que esconde la discriminación de la mujer exige una actitud valiente y decidida. Sobre todo porque en ese territorio las posiciones deben estar marcadas, sin medias tintas. Observar desde la indiferencia o la distancia no produce quebranto ni riesgo algunos. Pero el mensaje toma otro sentido y llega con otros sonidos cuando se ha sufrido esa situación en primera persona; entonces las palabras se perciben como dardos que remueven la conciencia. Así sucede en el presente relato cuyo personaje principal es una superviviente que, en el marco de un congreso universitario sobre discriminación por género y trabajo, recibe toda suerte de contenidos, técnicos y elaborados, sobre la igualdad de oportunidades entre mujeres y hombres. Y al someter de forma espontánea toda esa información a los filtros de su crítica y experiencia alcanza unas conclusiones muy personales.

Palabras clave: discriminación, mujer, género, trabajo, decencia.

Abstract. Moving through the labyrinths that hides the discrimination of women requires a courageous and determined attitude. Especially because in that territory the positions must be marked, without half measures. Observing from indifference or distance does not produce a break or risk some. But the message takes on another meaning and comes with other sounds when that situation has been experienced in the first person; then the words are perceived as darts that stir the conscience. This is the case in the present story whose main character is a survivor who, in the framework of a university congress on discrimination by gender and work, receives all kinds of content, technical and elaborated, on equal opportunities between women and men. And spontaneously submitting all that information to the filters of his criticism and experience reaches very personal conclusions.

Keywords: discrimination, women, gender, work, decency.

"josedelruiz@hotmail.com 


\section{La introducción}

Amanecía en una calle cualquiera ${ }^{1}$. Y ahí estaba el lugar donde alguien había pasado la noche: unos cartones sucios junto a unas botellas de cristal vacías. También podían percibirse el hedor que desprendía el ambiente y los desperdicios que, indeterminados y de origen desconocido, todo lo invadían.

La persona que observaba hizo un gesto de desaprobación y optó por seguir la marcha hacia un congreso universitario sobre la dignidad en el empleo que estaba anunciado en el mismo edificio. Giró desde la calle lateral en que se encontraba y se dispuso a entrar por la puerta noble del inmueble, un palacete neoclásico cargado de historia y ahora sede de una institución académica de prestigio.

Tuvo alguna dificultad para sortear el acceso porque no estaba acreditada. Pero el entusiasmo que mostró por el tema y sus afinadas dotes de persuasión convencieron al comité organizador para franquearle la entrada. Y ello pese a lo especializado de la materia, el alto nivel de los ponentes y el prestigio de los invitados; pero la escasa asistencia de público hizo posible que las puertas del evento se abrieran a la curiosidad de la forastera.

Desde los preliminares pudo comprobar la importancia que tenían las palabras género y sexo en el tratamiento de los contenidos anunciados en el programa. Ya el presentador del acto, reputado catedrático, advirtió sobre la influencia de su significado en cuantas intervenciones y debates a partir de entonces se llevarían a cabo. Y que se debía poner mucho esmero en su uso porque las sensibilidades estaban a flor de piel por aquello del lenguaje inclusivo². Género, remarcó, según el Diccionario de la Lengua Española, supone participar de caracteres comunes. Y prosiguió diciendo: ...sin duda hay masculino y femenino pero también neutro, que entiendo es la situación más reconfortante porque, atendiendo al significado, conduce a un plano de equilibrio entre lo positivo y lo negativo. Así sucede tanto en la electricidad y en el conjunto de la ciencia como en el origen de los neutros latinos, propios del mundo de la gramática y de las letras ${ }^{3}$.

En suma, concluyó tajante, lo más práctico sería apostar por la tercera acepción, la que vincula el género al sexo no por el factor biológico sino por una adscripción puramente sociocultural ${ }^{4}$. Porque para nuestra Academia -y aquí empezó a subir el tono- el vocablo sexo queda ligado a una cuestión orgánica que históricamente ha venido determinando

\footnotetext{
${ }^{1}$ Como en todo relato, los hechos encuentran apoyo en sucesos reales. Aquí también el argumento y los personajes son, casi en su totalidad, fruto de la imaginación y voluntad del autor conforme al mejor provecho del guión.

${ }^{2}$ En su reciente ensayo El género y la lengua (Turner Minor, 2018), Pedro Álvarez de Miranda, catedrático de Lengua y miembro de la Real Academia Española, examina con tino la polémica sobre el particular debate entre quienes pretenden conseguir una sociedad más justa y los que entienden que no debe forzarse un proceso natural en la evolución del lenguaje, por cuanto los cambios lingüísticos no son fruto de imposiciones sino del acuerdo de la mayoría de la comunidad hablante. A este respecto refiere que el Gobierno español rechazó el informe de la Academia de la Lengua que en mayo de 2004 proponía como formas alternativas a la expresión violencia de género las de violencia doméstica o violencia por razón del sexo, más apropiadas desde el punto de vista lingüístico a juicio de la Ilustre Institución (p.18).

${ }^{3}$ Los verbos intransitivos antiguamente se llamaban neutros por carecer de complemento directo y estar relacionados con una acción intrínseca (como el correr, el nacer o el morir) sin objeto al que servir como hacen los transitivos cuando se escribe un libro o se dice la verdad (o la mentira).

${ }^{4}$ El propio Tribunal Constitucional en el fundamento segundo de su sentencia 145/1991, de 1 de julio, define el concepto de discriminación positiva como un tratamiento diferenciado perjudicial en razón del sexo donde el sexo sea objeto de consideración directa.
} 
posturas de enfrentamiento entre lo débil del femenino, que conduce a la discriminación, y lo fuerte del masculino, aunque sin duda esta particular dialéctica haya que tomarla en un contexto de crítica e ironía.

El auditorio entero, entregado de antemano por su reputación y las innumerables publicaciones que enriquecían su brillante carrera, le obsequió con un cerrado aplauso. Pero la cosa no quedó ahí. Todavía, repuesto de la emoción, tuvo fuerzas para rematar expresando que es justo un planteamiento objetivo, limpio y neutro, el causante de las patologías que vienen a contaminar las desviaciones del concepto, siempre impregnadas del elemento desgarrador de la fuerza y la violencia irracional; de ahí que necesariamente deba ser combatido a través del principio de igualdad de oportunidades y de un marco normativo que venga a corregir sus perniciosos efectos y equilibrar derechos y obligaciones ${ }^{5}$. Y un dato más: quede claro desde el principio que la discriminación no es algo que deba relacionarse o condicionarse a la voluntad del infractor porque a menudo se daña al margen de la voluntad de hacerlo. Y así -dice muy convencido- lo vienen sentando nuestros tribunales de forma reiterada. En este punto una sensación de satisfacción interior se apodera del orador y se irradia a los asistentes ${ }^{6}$.

Ahora sí: el acto queda inaugurado. La función puede empezar.

\section{El título}

Aunque el tema giraba sobre la dignidad del trabajo, el título era más complejo y detallado. Aprovechando la actualidad y los nuevos aires que todo lo invadían a propósito del cambio climático y la globalización, la ONU viene propiciando lo que llama Objetivos para un Desarrollo Sostenible ${ }^{7}$, loable empeño que hereda toda una tradición universal desde su fundación misma. Pero el título es lo de menos si alguna relación guarda con los contenidos a desarrollar ${ }^{8}$.

Se remarca que el 25 de septiembre de 2015 supuso una fecha para recordar, al menos durante los próximos quince años, porque la ONU ha fijado una nueva Agenda

\footnotetext{
${ }^{5}$ El influjo del principio de igualdad de género como derecho fundamental en el Ordenamiento Comunitario y en el conjunto del Derecho Social del Trabajo ha sido puesto de relieve por Belén López Insua en la monografía sobre esta materia El principio de igualdad de género en el Derecho Social del Trabajo (Editorial Laborum, Murcia, 2017), que remata con una reflexión final donde trata la brecha salarial, el autoempleo y otros aspectos que condicionan, restringen o mejoran su aplicación (p. 233).

${ }^{6}$ En efecto, tal es el criterio uniforme que contiene la sentencia del Tribunal Superior de Justicia de Madrid, de 23 de febrero de 2018 (rec. 1179/2017), cuando expresa que la vulneración de derechos fundamentales no queda supeditada a la concurrencia de dolo o culpa en la conducta del sujeto activo, esto es, a la indagación de factores psicológicos y subjetivos de arduo control.

${ }^{7}$ El Gobierno de España ha creado el Alto Comisionado para la Agenda 2030 con dependencia directa de Presidencia y con funciones de coordinar las acciones que se hayan de realizar en relación con la misma. Tiene publicado un Plan de Acción que abre con una palabras del Secretario General de la ONU donde puede leerse que el objetivo es la transformación de la sociedad, el medio ambiente y la economía por razón de dignidad humana, cambiando nuestra forma de pensar y nuestras conductas hasta integrar las nociones esenciales como planeta, justicia, prosperidad y alianzas.

${ }^{8}$ Los retos del futuro como principio del trabajo decente de la mujer, que bien podría representar una contradicción de conceptos porque un objetivo no puede ser nunca una casilla de salida sino de llegada. Aunque cabe plantear un recorrido constante en una espiral interminable.
} 
Mundial (llamada 2030) para avanzar como humanidad, como un solo sujeto. Por eso no pueden faltar las buenas intenciones que toman rostro de objetivos, imprescindibles para entender que no todo responde a un mero juego de palabras ${ }^{9}$. Sobre ese esquema y sus limitaciones se desarrolla la intervención.

Los propósitos se formulan como si fuesen una meta a la vista y alcanzable a toda costa, como si en esa tarea monumental todos estuviésemos comprometidos, ricos y menesterosos, gobernados y gobernantes, sabios e ignorantes, trabajadores activos y ociosos. El fin de la pobreza y el hambre cero tienen un semblante ingenuo. La salud y la educación se muestran recurrentes. Lo medio-ambiental esta descrito en los objetivos relativos al agua, la energía, la innovación y el clima, entre otros. Pero sin duda los que despiertan el mayor interés por el tema que se desarrolla en la sesión son los referidos a la igualdad de género, el trabajo decente y el crecimiento económico, la reducción de las desigualdades y, quizá, el relativo a la paz, la justicia y las instituciones sólidas.

En fin, muchos pilares para anclar un sueño milenario muy difícil de conquista. Sobre todo en un mundo global donde la llamada posverdad parece que se ha instalado como una constante distorsión de la realidad capaz de alterar su percepción mediante la manipulación de percepciones y conductas, conforme a la definición que el Diccionario hace de ese neologismo. 0 quizá pueda tratarse solo de una alegoría donde la realidad se asienta en el nombre que la describe y no en su contenido material creando la ilusión del relato ${ }^{10}$.

A medida que se suceden las intervenciones asaltan a la cabeza de la neófita una serie de comentarios marginales (siempre válidos y oportunos) que no llega a procesar ni ordenar como le gustaría. Por ejemplo, al tratar sobre los colectivos vulnerables y género ${ }^{11}$, una de las ponentes propone revisar el concepto de vulnerabilidad para a continuación reconstruirlo, esto es, deshacerlo analíticamente en su distintos componentes, según más tarde pudo saber tras consultar el diccionario. Y de pronto se ve ya en una sala quirúrgica de operaciones ya en una laboratorio de alta cocina moderna. ¡Ay las palabras -se lamenta-, cuántas trampas encierran y qué extraños laberintos construyen! ${ }^{12}$

${ }^{9}$ En el breve y refulgente Prólogo al estudio de Luis María Cazorla El lenguaje jurídico actual (Editorial Aranzadi, Cizur Menor 2007) el profesor García de Enterría identifica el mundo jurídico con un vasto e interminable rumor de palabras a las que otorga la cualidad de recomponerse con nuevas palabras cuando sufren alguna clase de quebranto, siempre con el objetivo de ordenar la vida social para dirigirla hacia la justicia y la seguridad (p. 16).

${ }^{10}$ Sobre este particular resultan muy provechosas las enseñanzas del profesor Jorge Urrutia en La verdad convenida, Literatura y Comunicación (Editorial Biblioteca Nueva, Madrid, 1997), quien ya en la Advertencia preliminar, citando a Mallarmé, refiere que lo que distingue la palabra rosa de una rosa es la ausencia de cualquier rosa (l'absence de toute rose), adentrándonos en el insondable mundo fronterizo de la ficción y la realidad, de las construcciones culturales y la complejidad de los hábitos y convenciones (p.12).

${ }^{11}$ El concepto de trabajador especialmente sensible se desarrolla por la profesora Amanda Moreno en la monografía que estudia la prevención de riesgos laborales de este grupo específico (La prevención de risgos laborales de los trabajadores especialmente sensibles. Tirant lo Blanch, Valencia, 2010) dentro del cual ocupan lugar preferente las mujeres trabajadoras, trazando un riguroso análisis de la normativa aplicable a la protección y salud de las mismas tanto en el desarrollo de su trabajo como en consideración al estado propio de maternidad (p. 186).

${ }^{12}$ Para ahondar en el significado de las palabras, y advertir sus ecos, sentidos y latidos, son de obligada cita las reflexiones luminosas de Emilio LLedó en toda su obra, que se condensa en las conversaciones que integran el texto Dar razón (KRK Ediciones, 2017). Comentando el valor del lenguaje escrito, el pensador nos alerta sobre el mundo de superlenguajes que nos rodea, de superinformación donde no se oyen más que fórmulas y palabras trilladas y desprovistas de semilla inmortal que solo sirven para, en palabras de Platón, cultivar el olvido (p. 204). 
$\mathrm{Su}$ asombro se incrementa cuando la proponente considera esta tarea como un prius $^{13}$, que nuestra atónita espectadora no llega a entender del todo pues si antes le chocó que una palabra pudiera demolerse para luego volverse a levantar ahora no sale de su asombro cuando además se reclama urgencia para llevar a cabo tal empresa ${ }^{14}$.

¡Cuántas generalidades y lugares comunes para referirse a un problema, el de la vulnerabilidad, de la que ella se considera experta! Por ello frunce el ceño cuando oye hablar de las diversas situaciones a que, entendidas como factores de protección, puede conducir la llamada contributividad (luego se entera de que esta palabra/cualidad no está registrada todavía por la Academia de la Lengua) y la profesionalidad (ésta sí figura y se entiende como una virtud en el ejercicio de toda actividad hecha con capacitación y aplicación relevantes). Esta idea le despierta de súbito una mueca de ironía que trata de disimular cuando se alude a un contexto de realidad líquida y a la problemática que encierran los hogares monoparentales y monomarentales ${ }^{15}$. Puro estado gaseoso -se dice-, expresión de vanidad que tiene que corregir cuando se da de bruces con una reflexión muy interesante que llega a conmoverle: la presunción de no-vulnerabilidad impide visibilizar necesidades a proteger y sus correspondientes políticas sociales. Frase redonda y verdad absoluta.

La condición de mujer en algunas tradiciones culturales acelera el riesgo de sufrir discriminación por la asunción de responsabilidades familiares que solo puede ser combatida por la educación y el ejemplo en casa ${ }^{16}$. Nuestra protagonista se emociona al oír estas palabras; sabe bien de lo que se está hablando. Además ${ }^{17}$-piensa- si con el género se daña al débil aquí también sucede lo mismo: temporalidad y bajos salarios son su rostro; jornadas parciales y déficit de formación en multitud de sectores productivos, su consecuencia. Pero esto es solo el reflejo de una situación habitual que se repite. Y que se consiente. Hay mucho de liturgia en este comportamiento presidido por la resignación y la esperanza en el más allá.

En este punto le viene a la memoria un criterio de discriminación que en su experiencia personal no puede pasar desapercibido y que siempre rebrota con especial protagonismo: su vivencia como madre ${ }^{18}$ le truncó las expectativas de promoción y ello le hace perder el hilo de la exposición porque se ve transportada a un lugar borroso del pasado, que siente como una herida todavía pendiente de cicatrizar y al que nunca hubiese querido regresar.

\footnotetext{
${ }^{13}$ Tal vocablo en latín tiene un doble uso: es adverbio que se traduce como antes, primero; pero también es el neutro de prior/prioris, sustantivo con igual significado para señalar lo primero, lo precedente.

${ }^{14}$ Por su contexto cabe entender que se relaciona el vocablo con un factor de prioridad para distinguir la vulnerabilidad del no empleo frente a la precariedad laboral.

${ }^{15}$ ¡Ojo!, marental no se opone a parental. De hecho la primera palabra no está todavía admitida y sí la segunda, de parentalis, relativo a los padres; en el diccionario latino figura referido no solo a los padres sino también a los parientes en general.

${ }^{16}$ Debemos estar al concepto amplio que la propia Ley Orgánica 3/2007, de 22 de marzo, de igualdad efectiva entre mujeres y hombres, establece para definir los precisos contornos de la discriminación directa. En su artículo 6.1 reproduce casi en su integridad los términos del artículo 2 de la Directiva 54/2006, de 5 de julio, para identificarla con la situación en que se encuentra una persona que sea, haya sido o pudiera ser tratada en atención a su sexo de manera menos favorable que otra en situación comparable.

${ }^{17}$ Otros factores que potencian la vulnerabilidad son los de naturaleza jurídico-laboral que se añaden de forma espontánea y que son consecuencia de aquéllos.

${ }^{18}$ El estado de salud y el hecho biológico de la maternidad son potenciadores del riesgo a sufrir perjuicio y daño. A ello se añade un tratamiento protector muy distinto en función de la clase de contingencia y trayectoria de cotización.
} 
Cuando el discurso avanza de forma mecánica y desemboca en los terrenos de la vulnerabilidad del trabajo autónomo ${ }^{19}$, no cabe sino asumir tan evidente conclusión por vía de sentido común y entregada naturalidad. 0 cuando se descubre al auditorio, como si de una verdad revelada se tratara, que hay riesgos que no dependen de la voluntad personal sino de factores ajenos y externos, solo se le ocurre rumiar para sus adentros un irreverente $i Y$ ?, al que añade burlona:

- ¡Ah, o sea, que estamos describiendo una realidad cambiante que requiere la elaboración constante de reflexión y estudio! Pues sumémonos al carrusel! ${ }^{20}$

Y como herramienta final para superar la pobreza se habla de la Agenda 2030 como si de una pócima milagrosa se tratara. Ya solo el título nos abre el apetito bienhechor y concilia con los mejores sentimientos: transformar nuestro mundo. En fin una nueva declaración de derechos humanos para, quizá, ser incumplida del mismo modo que con otros viejos modelos ha sucedido a lo largo de la historia ${ }^{21}$.

\section{Desarrollo de la sesión}

El núcleo de las intervenciones se centra en la igualdad de género: la discriminación y la violencia sobre la mujer ${ }^{22}$ son sus peores lacras. Es un derecho humano sobre el que se asientan la paz y el progreso. Se ha avanzado considerablemente pero falta mucho más. Sin duda hay agresiones específicas contra la mujer lo que impone un criterio de especialidad, de discriminación positiva, aunque solo sea para concienciar. Eso como herramienta de choque debe admitirse, aunque la solución debe venir de un planteamiento neutro: jésta es la palabra! Neutralizar la tensión entre órganos (sexo) y grupos (género) para promocionar, incluso exaltar, la integración de todos. Es curioso advertir el distinto trato que la Academia da a los términos sexo débil y fuerte: al primero le da sentido despectivo; y al opuesto, otro de carácter irónico. Es decir, la debilidad juega como defensa en el primer caso; y como deformación en el segundo: dos polos que deben relativizarse y con tendencia a rebajar el tono.

\footnotetext{
${ }^{19}$ La profesora María Teresa Alameda realiza un estudio muy completo sobre esta materia (Trabajo autónomo decente de la mujer, en Blázquez Agudo, E.M (Dir.)., Los ODs como punto de partida para el fomento de la calidad del empleo femenino, Editorial Dykinson, Madrid 2018) a propósito del debate mundial que sobre la materia se viene desarrollando con aportación de reflexiones muy elaboradas que pasan por la superación de las manifestaciones de trabajo no decente (mediante el papel clave que en la defensa de los intereses profesionales corresponde a sus instancias representativas y sindicatos) y el fomento de asociaciones y cooperativas que vengan a propiciar el valor de la solidaridad, clave -dice la autora- en la conquista de espacios y derechos (p. 129).

${ }^{20}$ Por supuesto todo admite manifestaciones y grados diversos; y un remedio infalible frente a esto lo constituye el trabajo decente. Pero hay un miedo endémico a la salida del mercado de trabajo por no aceptar la precarización de las medidas. Otra solución puede ser el avance en una nueva óptica que tenga como centro a la mujer en el análisis y en las políticas públicas (el ginecentrismo del que cierta doctrina habla, es mero neologismo compuesto con significado fácil de comprender pero no admitido todavía en el Diccionario de la Lengua Española).

${ }^{21}$ Se abre un marco de reflexión distinto con la expectativa puesta en el Plan Director por un Trabajo Digno 20182020, contenido en la resolución de 27 de julio pasado.

${ }^{22}$ Sobre la dimensión laboral de la violencia de género resulta imprescindible la consulta del Comentario que con ese mismo título hace la profesora María Fernanda Fernández López a la Ley Orgánica 1/2004, de 28 de diciembre, reivindicando ya desde su Introducción la respuesta multidisciplinar que debe darse a tan odioso fenómeno (Editorial Bomarzo, Albacete 2005, p. 10).
} 
Con este arranque, la intrusa comienza a sentirse reconfortada en su elección de pasar el día en ese territorio comanche que le gusta, rodeada de personas cultas que tanto tienen que aportarle. Y no solo eso; también le han dicho que su papel es importante para la consecución de los objetivos, combatir la pobreza y lograr un trabajo decente para todos. Sobre este ideal, acariciado desde la noción abstracta que representa el desarrollo económico, hay estadísticas de muy diverso contenido y autorías que nos proponen una concienzuda reflexión sobre las desigualdades y la erradicación de la miseria. Y de aquí es fácil volver a los conceptos inagotables de trabajo decente y calidad del empleo, que en la agenda institucional se conciben como un gran desafío. Todo en un contexto de frases hechas y nociones escurridizas como la productividad laboral y las tasas de desempleo ${ }^{23}$.

Una cara de circunstancia y rechazo se le pone cuando de forma solemne se anuncia que debemos evitar las conjeturas de futuro o las fantasías alarmistas que distorsionan toda expectativa razonable de favorecer (y alcanzar) el objetivo del trabajo decente ${ }^{24}$. Pero sobre todo no puede contener un gesto de ironía cuando refiriéndose a la necesaria reducción de las desigualdades advierte que la disertación sobre tan prometedor aspecto destila generalidades, empezando por el término reducción que se le antoja difuso y hasta complaciente ${ }^{25}$.

Y piensa que guarda perfecta coherencia con lo escuchado hasta ahora, pues también aquí las metas se muestran imprecisas y a futuro ${ }^{26}$ : crecimiento de ingresos, inclusión social, igualdad de oportunidades, aumento de cuotas y participación de los países en desarrollo en los organismos internacionales de naturaleza económica y financiera. Pese a todo -imagina optimista- esta música suena dulce y agradable. Por eso cuando irrumpen otras referencias a la paz o la justicia y se habla de instituciones sólidas confirma con asentimiento primario y deleite que es difícil no estar de acuerdo con la belleza que desprenden las palabras de un texto lleno de buenas intenciones. Sobre todo si se habla de valores universales como los dos primeros. Pero al mismo tiempo le cuesta dejar de reaccionar con indignación cuando un escalofrío (de intensidad media) le recorre el cuerpo pensando que en ese marco idílico debemos enfrentarnos a fenómenos incompre-

\footnotetext{
${ }^{23}$ Un aspecto básico para el desarrollo económico es sin duda el medio ambiente como factor de apoyo al trabajo decente. Un dato sobrecogedor lo representa el alto índice de trabajadores con un empleo no regulado. También la llamada brecha salarial es tan real como descriptiva con tintes más estadísticos y sociológicos que jurídico-formales, sobre todo porque es una tendencia que necesariamente se debe ir corrigiendo resultando muy compleja y diversa según ámbitos. Las posturas combatientes, beligerantes y enfrentadas (frentista no está reconocido en el Diccionario de la Lengua Española) en materia de promoción, techos de cristal, cuidados de personas y trabajo doméstico solo son justificables, a mi entender, desde un aspecto dinamizador del debate pero sin trincheras ni ropajes de apariencia que impidan o dificulten el diálogo.

${ }^{24}$ Incluso los cálculos fundados en criterios científicos que auguran tal diagnóstico o resultado, ...y que casi nunca se cumple sobre todo si combina cuantías elásticas y largos periodos de tiempo; como por ejemplo el que augura que hasta el año 2030 se necesitarán casi quinientos millones de puestos de trabajo en todo el mundo para quienes van a acceder por primera vez al mercado laboral.

${ }^{25}$ Sin duda es una visión amplia y comparativa entre países que hace referencia a datos globales, políticas universales, ingresos per capita, aranceles, exportaciones y trabajo migrante. Sus metas parten de datos que reflejan un panorama sombrío para las comunidades en desarrollo con pobreza, mortalidad infantil y materna, desprotección social y gasto farmacéutico.

${ }^{26}$ En la Conferencia Nacional Tripartita sobre la iniciativa El futuro del trabajo que queremos, celebrada en Madrid el 28 de marzo de 2017, el propio Director General de la Organización Internacional del Trabajo manifiesta que, tras casi cien años de historia que ahora se cumplen, resulta inevitable impulsar la reflexión sobre el futuro del trabajo que arroje conclusiones y resultados sólidos (Vol. I, p. 28).
} 
sibles que ofenden la condición humana. Y cuando se dice que entre las instituciones más corruptas están la judicatura y la policía, que los índices de evasión fiscal son alarmantes, que un porcentaje muy elevado de niños ni está registrado ni acude a la escuela por razón de conflicto bélico y que la tercera parte de los presos no tiene sentencia que les condene, queda impresionada por dardos (la ponente lo llama anomalías) que necesariamente conmueven su delicado estado emocional ${ }^{27}$.

Ya repuesta, espera el comienzo de la siguiente ponencia.

\section{Igualdad e inserción}

Observa curiosa cómo sigue el desarrollo de la sesión: esto debe ser una cuestión de orden, se dice ingenua, porque primero se parte de los datos estadísticos para fijar la base material de cada uno de los derechos que a continuación se tratan. Claro, por eso uno de los conferenciantes dice que éstos son solo las herramientas que nos llevarán al conocimiento. Y nos recuerda que cada cierto tiempo estos propósitos universales se vuelven a repetir porque algo falla. Se acuerda de un plan anterior de la ONU llamado Objetivos del Milenio que fracasaron precisamente porque no se tuvieron en cuenta los gráficos, estudios comparativos, diagramas y demás instrumentos que nos proporcionan seguridad en los diagnósticos. Y aventura que ahora somos más fuertes. Y que por eso los referidos objetivos serán en lo sucesivo más fáciles de conseguir. Pero siempre -advierte convencido- hay que contar con determinadas variables que pueden arruinar todos los cálculos. Evidentemente un rumor invade la sala procedente de un auditorio entregado al conocimiento y curriculum del profesor que se ve en un aprieto cuando espontáneamente uno de los asistentes, entre bromas y veras, le pregunta si debemos fiarnos o no de los cuadros que durante la media hora precedente se ha esmerado en defender.

De los cuadros y diagramas se pasa a los contenidos: la inserción es palabra clave. Y la curiosidad de la intrusa le lleva de nuevo a preguntarse ingenua de qué clase de proceso inclusivo se trata. Entonces observa con asombro cómo la ponente en esta materia llega a mostrar verdadero enfado cuando se entera de que los plazos y el grado de compromiso han sido incumplidos por el Reino de España. Lo que vuelve a suceder cuando censura el trabajo forzoso en la infancia que califica como expresión de auténtica esclavitud ${ }^{28}$. No puede reprimir una mueca de satisfacción y empatía cuando se denuncian estas prácticas y se condena sin paliativos la conducta permisiva, incluso hipócrita, de los Estados infractores ${ }^{29}$.

\footnotetext{
${ }^{27}$ Consecuentemente las metas se imponen por sí mismas: seguimos en un discurso estéticamente impoluto que sin duda toda persona honesta suscribiría. Pero que encuentra muchos opositores e inconvenientes sobre los que uno destaca: el miedo a llevarlo a efecto, los intereses silentes y el egoísmo mal entendido como supervivencia.

${ }^{28}$ El delito contra la libertad y los derechos de los trabajadores es un tipo penal de escasa, por no decir nula, aplicación práctica porque se entiende de forma restrictiva; basta un repaso a la jurisprudencia del Tribunal de Justicia de la Unión Europea para confirmarlo. Sin duda hay esclavitud y trabajo forzoso y la última ratio es el Derecho Penal.

${ }^{29}$ Hay que hacer diagnósticos, se concluye, porque la comentada Agenda no solo contiene principios y declaraciones generales sino sobre todo herramientas. Y prueba de ello es el plan de implementación que en España ha venido a dotar a la Inspección de Trabajo de un calendario de estrategias para combatir el fraude en la contratación durante el pasado año de 2018 y lograr el objetivo contenido en la Meta 8.7 relativa al trabajo decente.
} 
La igualdad en el acceso a los recursos económicos permite una consideración genérica al llamado techo de cristal. 0 mejor, un alegato en contra a la distinta promoción profesional (y trato salarial) entre mujeres y hombres. En este punto la oyente accidental se estremece: ella sabe mucho de techos y de sus carencias también; y de la sustancia vítrea y delicada que los determina y hace transparentes solo puede aportar su propia experiencia que dejamos para más tarde. En efecto al mercado de trabajo se han incorporado muchas mujeres, pero....jSiempre hay un pero!, reflexiona resignada.

Y la ponente lo certifica: en efecto, sobre el papel rige la igualdad pero $i y$ la letra pequeña? Esa que nos aparta a las mujeres -piensa ella- a las sobras de una libertad de mercado que elige al fuerte, al competitivo, a aquellos que no sufren quebranto en su salud por causa de la maternidad y de otros procesos que solo a la mujer afectan ${ }^{30}$. Ésa es la clave: cegar la visión machista que hace de los hombres superiores en la competencia y adquisición de un puesto de trabajo ${ }^{31}$. Sobre todo cuando por sentido común las tensiones serían fácilmente superables sin necesidad de acudir a universales principios de Derecho y enciclopédicos tratados de Ética y Biología ${ }^{32}$. Y este anhelo nos conduce a la reparación del daño que difícilmente puede lograrse en plenitud porque su huella nunca desaparece ${ }^{33}$.

\section{La mujer en el centro del debate}

Hasta el momento la novicia ha entendido lo fundamental; algunas palabras se le hacen extrañas pero en conjunto el mensaje le llega y despierta su sentido crítico. Y recuerda una idea que tiene grabada desde hace tiempo sin que termine de situarla en el tiempo ni poner cara a su autor: loable propósito el de trenzar historias para domesticar la rigidez del texto jurídico y hacerlo universal y entendible. Porque al final todo es un laberíntico y reparador juego de palabras.

Sumida en el aroma de tal reflexión, un segundo paquete temático homogéneo se abre ahora a los derechos de la mujer y su interés se ve reforzado porque está aquí para reivindicarse como oyente y trabajadora a futuro; y sobre todo como mujer, que lo es desde la cuna y por convicción. Por ello se le encoge el corazón cuando la nueva ponente empieza a tratar el tema de las modificaciones laborales de tiempo y lugar y su ajuste debido a

\footnotetext{
${ }^{30}$ En el ámbito de la seguridad y salud laborales desde una perspectiva de género, destaca el estudio que la profesora Patricia Nieto realiza sobre la escasa respuesta que la negociación colectiva viene dando a la prevención de riesgos laborales en sectores con una importante segregación ocupacional y mayor impacto en las mujeres (Dimensión de género en el tratamiento convencional de la seguridad y salud laboral, en Blázquez Agudo, E.M., Informe sobre salud laboral desde la perspectiva de género, Instituto de Estudios de Género. Uc3m, 2017, p. 75).

${ }^{31}$ Todos los estudios coinciden en sostener que en igualdad de condiciones se contrata más al hombre que a la mujer sin que en este punto quepan las generalidades y los lugares comunes. En suma, hay que acabar con los prejuicios sexistas y casuística no falta a favor de este propósito.

${ }^{32}$ Afortunadamente los tribunales de justicia, cada vez más, aplican con mayor convencimiento estos criterios de lógica que conforman y complementan el ordenamiento jurídico.

${ }^{33}$ Las medidas de tutela antidiscriminatoria pasan a menudo por la restitución de los derechos vulnerados, que básicamente consiste en volver a la situación original pero presentando, como una de sus mayores disfunciones, la escasa sanción que comporta.
} 
las responsabilidades familiares de las trabajadoras ¡Ay si yo te contara!, se le escapa para sus adentros en expresión entre castiza y vanidosa.

Y mientras coincide en que, en efecto, flexibilizar el tiempo y el lugar de trabajo es un gran objetivo, sueña con el importante papel que juega la corresponsabilidad de los cuidados para acceder y mantenerse en el mercado laboral facilitando la conciliación de trabajo y familia ${ }^{34}$.

Y de nuevo las estadísticas y sus comparativas, donde destacan las que ilustran y enseñan. Pero también las que alarman y terminan por tensar aun más la cuerda de las diferencias entre los roles de género, las remuneraciones distintas y los espacios públicos y privados. En este punto, admite, los resultados que se muestran en las diapositivas son los que mandan y piensa de buena fe en la imparcialidad de las fuentes.

¿Por qué los cuidados están feminizados?, se pregunta la oradora con pasmoso candor tratando de ganar la complicidad de sus oyentes. Y de nuevo una respuesta infalible y retórica: por una cuestión cultural, aunque -exhorta seguidamente- debemos tender hacia el equilibrio. Y este principio es la fuerza matriz que nos impulsa para abordar tanto la inserción como el problema de las personas dependientes ${ }^{35}$. Sin duda la clave está en implicar al hombre en las tareas de cuidado. Porque es cierto que el empresario ve a la mujer fértil como un enemigo en potencia. Crueles (y dolorosas) palabras que suscitan la complicidad y aclamación del auditorio, a las que se suma nuestra protagonista. Porque tras pronunciar con rotundidad esa idea añade que vivimos toda una sinrazón que actualmente soportamos y que -esto es lo más duro- seguimos aguantando y consintiendo hasta cierto punto. Y sentencia: todo refulge sobre el papel pero cosa muy distinta es la práctica: ahí están los números sobre las excedencias por cuidado de hijos. Muchas menos de las que el sentido común y la realidad de las familias hace pensar ${ }^{36}$.

Que hay brechas de género, está claro. Pero buscar sus causas es responsabilidad de todos porque a menudo -se concluye- son atribuibles a comportamientos que no siempre la ley puede combatir por decreto sino que es preciso alimentar mediante marcadas actitudes desde la infancia. Consideración que nuestra espontánea remata con un pensamiento de su cosecha propia: es tarea de precalentar para luego disponer un buen horneado. Por ello las soluciones a este problema no admiten mensajes negativos ni generalidades ${ }^{37}$.

\footnotetext{
${ }^{34}$ Equilibrar es tarea difícil; pero en su etimología, en su llamada a la igualdad, está la clave de su cumplimiento. Así, el llamado trabajo informal ha sido propio de las mujeres y ello entraña mayor carga y desprotección social. En este punto las estadísticas no mienten y no faltan fuentes de las que beber aunque se acuda a lugares comunes. De ahí que la apuesta sea por la educación con voluntad de implementar nuevas medidas porque el modelo tradicional se muestra insostenible. Del obrero clásico, del proletario, hemos pasado a las personas enfermas y a los mayores, en definitiva a los débiles y vulnerables. Esta es la materia que a nosotros y al Derecho Social interesa.

${ }^{35}$ La ley incorpora una aspiración, la de conciliar pero es éste un propósito sin equilibrio: es vestir un santo para desnudar a otro. Y para ejemplo los turnos deslizantes en los Centros de Atención Primaria dependientes de las distintas Áreas Sanitarias, que saturan de profesionales el de mañana dejando el de tarde, paradójicamente, desprovisto de especialistas en pediatría.

${ }^{36}$ En el estudio que la profesora Gema Quintero hace sobre la protección a la familia desde una perspectiva de género (en Blázquez, E. M., Prestaciones de Seguridad Social y género. OISS, 2017) se pregunta, trazando un recorrido por la historia de la Seguridad Social española, si es posible llevarla a efecto desde una postura de neutralidad para terminar formulando unas valiosas aportaciones finales entre las que destaca la propuesta de su impulso a través de la responsabilidad corporativa de las empresas (p. 49).

${ }^{37}$ Aunque pueda admitirse la idea de que el hombre asciende y progresa de forma natural en su carrera profesio-
} 
Y tampoco procede tomar como referencia exclusiva ese paraíso de la economía y el empleo llamado mercado laboral, porque al margen de éste, hay otros ámbitos y espacios llenos de encanto con senderos por explorar ${ }^{38}$.

Y todo porque a mi juicio no se tiene cultura, dice ella; es decir, no se cultivan buenos hábitos que obliguen a implicarse en casa desde el origen. Sí, sí... ¡desde los cuidados básicos hasta la implicación diaria! Con estas prácticas, no habría que imponer corresponsabilidad alguna porque su flujo sería natural y nutriente. Palabras, sí... pero con etimología, sonido y sentido, remata ufana y satisfecha de su oratoria.

En este carrusel de propuestas y críticas se llega a tratar de los mecanismos de flexibilidad temporal. De las articulaciones y sus componentes. Y como todo cobra un tono abstracto y general se termina hablando de los derechos de ausencia. Hay fórmulas de trabajo flexible -se defiende- como son el trabajo a distancia, el realizado a tiempo parcial y el llamado trabajo compartido. También el contrato de grupo, un trabajo pendiente, y el del auxiliar asociado (esto lo añade una voz socarrona que atraviesa la mente de nuestra espontánea $)^{39}$. En definitiva, la tarea de conciliar vida laboral y familiar se muestra compleja porque, a la vista de lo que va exponiendo, es como si realmente ambos planos se mezclasen como amalgama que guardara la sorpresa de saber si realmente terminarán por coincidir o excluirse. Todo muy elemental en el cielo de las ideas pero muy difícil de aplicar en el fango de la realidad, masculla con cierta malicia en sus adentros ${ }^{40}$.

¡No a la concepción androcéntrica del Derecho y sí a la corresponsabilidad superando los lastres machistas! Cuando escucha este enunciado su ánimo se eleva y piensa, sagaz, que la ponente se lo ha quitado de los labios ${ }^{41}$. Es éste un tema descarnado donde confluyen sentimiento y pensamiento: otro difícil equilibrio cuya procedencia, en un empuje de brillantez desbordada, se atreve a situar en los vocablos latinos equalis (igual) y

nal, es indudable que la mujer, además y por el contrario, a menudo ve truncada la suya por razón de maternidad. Las medidas de conciliación pasan por flexibilizar la jornada y el lugar de trabajo, comprometiendo al hombre en las responsabilidades de familia y cuidados. Así se contiene en las últimas Directivas y dictámenes de la UE como la Propuesta de Directiva del Parlamento Europeo y del Consejo relativa a la conciliación de la vida familiar y la vida profesional de los progenitores y los cuidadores, y por la que se deroga la Directiva 2010/18/UE del Consejo, COM/2017/0253 final-2017/085 (COD).

${ }^{38}$ Nuestro Derecho Interno se inaugura con la ley 39/1999, de 5 de noviembre, que supone un notable avance pero se muestra incapaz de dar un giro en el plano de la corresponsabilidad y el equilibrio de los roles en la familia. Es la Ley Orgánica 3/2007 la que aporta sobre el papel un paso más, en particular sobre el uso conceptual y asexuado de progenitor. El futuro y los tímidos avances: el permiso parental retribuido hasta los doce años y su naturaleza intransferible durante los cuatro primeros meses.

${ }^{39}$ En este punto se cita inevitablemente el artículo 34.8 ET pero antes el 10 del mismo texto legal regula el trabajo en común y el contrato de grupo que lamentablemente pasan por ser figuras decorativas, en el conjunto de nuestro ordenamiento jurídico, y perfecto paradigma de una norma engañosa con finalidad claramente publicitaria. Así lo entiende Juan Gorelli en su Trabajo y necesidades familiares: la reducción y adaptación del tiempo de trabajo (Iustel. RGSS, vol. 48, 2018, p. 28). De igual modo el artículo 37.5 ET no sacia la necesidad de conciliar porque no cumple el sentido finalista de la reducción de jornada, a juicio de Marisol Herraiz en La gestión del tiempo de trabajo en el siglo XXI (p. 84).

${ }^{40}$ El derecho de desconexión tecnológica en Francia, introducido por Ley 2016-1068, de 8 de agosto de agosto de 2016, constituye ejemplo y muestra de respeto al tiempo de descanso.

${ }^{41}$ El vigente Acuerdo para el Empleo y la Negociación Colectiva (BOE de 18 de julio de 2018) y el Plan de Igualdad de la Universidad de Cádiz sobre equiparación de derechos en los permisos de paternidad, maternidad y lactancia (Boletín Oficial de la Universidad de Cádiz, Año IX, Suplemento 1 al número 122, de julio de 2011), resulta modélico para ilustrar esta idea e incorpora como Anexo un ilustrativo glosario de términos relacionados con la igualdad entre mujeres y hombres. 
equitas (igualdad), pasando este último al Diccionario como ecuanimidad y buen juicio o como compensación y armonía entre objetos diversos que actúan de contrapeso. Sin duda, se dice envanecida, es mi acepción preferida (la segunda) porque se refiere al cuerpo que con poco sustento no termina de caerse venciendo la ley de la gravedad. Toda una metáfora en el asunto que hoy nos reúne, concluye satisfecha de su aportación para sí misma.

La salud laboral es tema delicado. Una voz poderosa irrumpe en la sala para anunciar que trabajo y bienestar se requieren; y se aportan datos y más datos que alumbran conclusiones corroboradas por rutilantes estudios hechos al amparo de otros anteriores. Y mucha estadística, fría y mecánica estadística. Quieren demostrar a un auditorio entregado que ambos conceptos, aunque complementarios, a menudo entran en colisión. Y nuestra atenta advenediza no deja de pensar en la frase hecha, muy recurrente en estos casos, según la cual el trabajo mata; o por lo menos enferma, piensa suavizando la expresión. Claro que también repercute directamente en colectivos especialmente sensibles, lo que ha determinado que la evolución legislativa sobre protección a la mujer haya considerado la necesidad de requerir una evaluación de riesgos específica en los casos de embarazo y maternidad ${ }^{42}$.

Un clamor general de asentimiento se propaga por la sala cuando, tajante y decidida, la joven ponente (quizá ya madre o en fase preparatoria, piensa entrometida la intrusa) viene a decir sin disimulo que en este punto la norma no se cumple, circunstancia que corrobora el mismísimo Tribunal Supremo en sentencias muy recientes. Y ello es porque a menudo el texto legal no es claro o porque no se atreve a regular situaciones fronterizas entre el trabajo autónomo y el prestado por cuenta ajena ${ }^{43}$, forzando que los tribunales se pronuncien de forma contradictoria y sesgada. Un remedio que se propone consiste en llevar estos temas a los planes de igualdad en las empresas para despejar todas las dudas y contribuir a la efectiva protección de la maternidad: un murmullo de aprobación se percibe en el ambiente como si se tratase de una bocanada de aire fresco. La espectadora en tránsito suspira emocionada a pleno pulmón.

Es justo el momento de un cambio de rumbo: las discriminaciones por edad y discapacidad en el marco de la Seguridad Social también tejen un tupido entramado de situaciones que llama la atención de la oyente accidental. Elaborado por supuesto desde la perspectiva de género, obliga a sentar como base de la disertación la existencia de discriminaciones múltiples. El discurso se hace coherente porque es fácil identificarse no solo con el presupuesto sino con sus distintos objetivos que, claro está, actúan interrelaciona-

${ }^{42}$ Y ello conforme al artículo 26 de la Ley de Prevención de Riesgos Laborales y a la jurisprudencia europea del Tribunal de Justicia, de la que es muestra la sentencia recaída en fecha de 19 de septiembre de 2018, que aclara las cuestiones planteadas por el Tribunal Superior de Justicia de Galicia acerca de la aplicación de las Directivas 92/85, sobre seguridad y salud de las trabajadoras embarazadas, y 2006/54, relativa a la igualdad de trato y discriminación por razón de sexo.

${ }^{43}$ El trabajo autónomo irregular representa manifestación de economía sumergida que cabe combatir mediante una serie de propuestas de reforma legislativa que la profesora Cristina Aragón formula con el propósito de eliminar los desincentivos que impiden su adecuada inclusión en el RETA y que analiza desde una doble perspectiva: una, la referida de la financiación del sistema, y otra que vincula a la acción protectora en los supuestos de pluriactividad (Propuestas de reforma legislativa, en materia de Seguridad Social para hacer emerger el trabajo autónomo irregular, Documentación Laboral, número 107, 2016. p. 107). 
dos: género sí pero también edad y discapacidad, entre otros factores. Hasta llegar a sus implicaciones en el mercado laboral y, cómo no, proyectar sus consecuencias al propio sistema de la Seguridad Social ${ }^{44}$.

Cuando se dice con todo convencimiento que la vejez ha evolucionado a jubilación, por fuerza se impone una reflexión sobre el llamado lenguaje inclusivo; asumir sus debilidades implica no llegar al esperpento: poeta y poetisa valen igual. Y una persona mayor que antes estaba estigmatizada como viejo ahora es un jubilado que posiblemente tenga una agenda repleta de proyectos y compromisos. Tan clarividente reflexión conduce a preguntarse para sus adentros, con sordina y entre dientes -sentando cátedra, se dice divertidapor qué entonces no aplicar sin complejos el vocablo trabajadores al conjunto de personas asalariadas del mismo modo que en todos caben sobreentendidos sin excepción los componentes de un grupo o en todas conviven pacíficamente cuantas personas lo integran ${ }^{45}$.

Las equiparaciones son a menudo estériles por restringidas y accidentales. Esta deducción pudiera ser cosa de estadísticas pero un paseo por la historia más reciente lleva a la evidencia: hay más pensionistas hombres que mujeres y en la carrera de cotización de éstas hay lagunas que tienen fundamento no solo en el hecho biológico de la maternidad sino también en lo que con acierto semántico y descriptivo los estudios de género llaman suelo pegajoso ${ }^{46}$. Por supuesto que hay brechas, como demuestra un dato fuera de toda duda: que las pensiones menores se perciben por la mujer y en mayor número deben complementarse hasta alcanzar la cuantía mínima.

Ante este panorama poco se puede objetar. La evidencia se impone: las mujeres vienen soportando mayor carga familiar y su envejecimiento activo implica la continuación de su vida laboral más allá de la edad legal de jubilación ${ }^{47}$. Aquí es difícil sujetar el aplauso cuando se hace una apostilla a favor de las ficciones en Derecho pues tienen mucho que decir como factor de corrección de las discriminaciones y como expresión de justicia y equidad. Aunque se materialicen con formulaciones aritméticas de muy dudoso gusto, en un contexto donde predomina la oportunidad y la técnica más que la voluntad de conceder abiertamente pensiones dignas ${ }^{48}$.

\footnotetext{
${ }^{44}$ En este apartado deben destacarse las reflexiones de Eva María Blázquez en la obra que dirige, Los ODs como punto de partida para el fomento de la calidad del empleo femenino (Editorial Dykinson, Madrid 2018), cuando trata los referidos elementos en el contexto de la Seguridad Social y estudia los efectos de su interconexión agravados por la brecha salarial, la discriminación múltiple y su repercusión en la protección social subsiguiente (p. 71).

${ }^{45}$ En nuestra Lengua se percibe con nitidez la falta de identificación entre género y sexo; por eso se acude al grupo de los llamados nombres epiceno que tienen un solo género gramatical y sirven para referirse tanto a seres de sexo masculino como femenino. Son ejemplos los vocablos persona, criatura, víctima, figura o eminencia. Aquí -dice el profesor Álvarez de Miranda- el femenino gramatical asume la representación tanto del masculino como del femenino sexuales, de los hombres y de las mujeres. Sostiene con cierto atrevimiento el académico que a ningún hombre se le ocurrirá sentirse discriminado o invisibilizado por ello (El género y la lengua, Turner Minor, 2018, p. 24); aunque toda norma tiene sus excepciones, podría oponérsele.

${ }^{46}$ En el glosario antes referido que figura en el Plan de Igualdad de la Universidad de Cádiz se entiende como aquel conjunto de obligaciones impuestas a la mujeres para que no abandonen el ámbito de lo doméstico, representando una fuente de conflictividad por el considerable esfuerzo físico y emocional que comporta y la frustración de conseguir el debido equilibrio entre las exigencias externas y las demandas que llegan desde el hogar y la familia.

${ }^{47}$ Interesante el criterio judicial humanizador sobre el requisito de la carencia específica en los casos de lagunas de cotización: considerar como paréntesis el lapso de tiempo que no se cotizó.

${ }^{48}$ Para contrarrestar los efectos de la falta de cotización se acude al remedio de las cotizaciones ficticias por parto y cuidado de hijos. Se critica esta clase de medidas porque al reconocerse solo a la mujer se perpetua el reparto de roles,
} 
También resulta interesante la ficción de considerar cotizada por jornada completa la reducción en caso de guarda legal o atención a otros familiares en periodos variables siempre susceptibles de mejora. En fin, todo un conglomerado de supuestos complejos que con frecuencia atraen la atención de la jurisprudencia y la buena doctrina ${ }^{49}$. Porque la solución final pasa por las seductoras palabras de equiparación, flexibilidad y corresponsabilidad.

El tratamiento de la discapacidad está repleto de viejas huellas y cicatrices siempre actualizadas. Y también de estadísticas. Eso mismo sucede cuando se ponen en relación con la edad los distintos sectores de actividad y la desigual clase de contingencia: en todos los ámbitos se pueden hacer números y enfrentar datos para llegar a toda suerte de conclusiones y evidencias. Y ello mediante una infinidad de reglas técnicas que con frecuencia no responden al interés general o a las políticas sociales sino a los objetivos presupuestarios de la Tesorería de la Seguridad Social. Eso mismo puede sostenerse de la política de contratación de personal en el conjunto de la Administración, incluida la Universidad (de ésta y de todas, se malicia con sutileza) en que la utilidad económica se impone en detrimento de otros valores y con fomento de la precariedad del trabajo ${ }^{50}$.

El principio de la no contributividad en el sistema de Seguridad Social queda asociado al género femenino y se satisface a través de impuestos. En este apartado se invierten los factores lógicos; primero se fija el concepto de incapacidad y después se analiza desde una perspectiva de género ${ }^{51}$. Y una conclusión obvia: la edad es un elemento que va a influir en mayor medida que la discapacidad en la protección no contributiva de la Seguridad Social porque en la mujer tal clase de prestación se muestra como alternativa a la viudedad.

Obvio y radical son calificativos que, a duras penas, se contiene de participar sonoramente (es decir, gritar con estruendo) a un auditorio entregado y conforme.

\section{La quimera del trabajo decente}

Los vapores del emprendimiento, del riesgo y de la aventura comienzan a inundar la sala cuando la siguiente ponente anuncia que debe darse un impuso al papel de la mujer en un ámbito ajeno, pero complementario, al del trabajo asalariado ¿Qué es eso de fichar y estar recibiendo órdenes en régimen de dependencia? Interesante y prometedor. Aunque

razón que podría justificar el que se hicieran extensivas de forma general si en lugar de atender al vocablo parto (limitado a la mujer) se considerase el hecho del nacimiento mismo.

${ }^{49}$ Así, la STC 61/2013, sobre cotización en los contratos a tiempo parcial, al entenderla discriminatoria contra la mujer. La ley 1/2014, de 28 de febrero, vino a corregir los efectos perversos de la situación previa, aunque en el premio a la contribución demográfica que supone el reconocimiento a las mujeres de un incremento en las bases reguladoras por nacimiento de hijos (en porcentajes del 5\% al 15\%) también cabe la crítica por discriminación positiva.

${ }^{50}$ Sobre esta comparativa podemos extendernos en las luminosas reflexiones con que Nuccio Ordine nos deslumbra en su manifiesto La utilidad de lo inútil (Acantilado, Barcelona 2018), cuya segunda parte tiene por título La universidadempresa y los estudiantes-clientes postulando la prevalencia del saber frente a los criterios mercantilistas y de recorte en las inversiones educativas (p. 77).

${ }^{51}$ Interesante, por cosmética, la reserva del $2 \%$ en las empresas de más de 50 trabajadores como incentivo del empleo de las personas con discapacidad y los porcentajes de feminización que en este grupo se registran como expresión de protección social contributiva. 
para qué vamos a negarlo, la gran mayoría de la población piensa que eso de establecerse como autónomo es fruto de la necesidad y casi nunca se plantea como un objetivo valioso. Que quede claro (y mira con recelo a quienes componen la mesa), todos hablando de la cuestión de género, del trabajo decente y otra suerte de vulnerabilidades pero ninguno se aventura al riesgo de poner un negocio. Mejor y más seguro, al calor de un empleo público conseguido con honestidad y en competencia con otros en lícita oposición, conforme a los sacrosantos principios del mérito y la capacidad -se deleita con íntima picardía-.

Resulta novedoso, original y hasta curioso calificar las empresas con el tinte de sus promotores. Lo femenino sin duda está en el Diccionario indicando todo lo relativo a la mujer $^{52}$, incluso le sorprende conocer que -a juicio de la profesora ponente- en Apuleyo (ahora conoce que este escritor romano es autor del Asno de Oro) el vocablo femen-feminis hace referencia a la parte interior del muslo, es decir, por donde se toca el uno con el otro, en contraposición a femur-oris, que en Cicerón aparece como el muslo por de fuera, esto es, por las partes en que no toca el uno con el otro. Esta versión (tan atrevida y sicalíptica como real y fundada) ha dado lugar a que se dude de su veracidad pues convive con otras leyendas de origen popular y llega al mismo San Isidoro de Sevilla que en sus Etimologías relaciona dichos vocablos para contrastar las distintas cualidades que separan a una y otro ${ }^{53}$. Tampoco puede encontrar origen en aquella otra que relaciona el término con ciertos inquisidores de la Edad Media cuando identifican lo femenino con fides minus, pretendiendo de forma grotesca exaltar la infidelidad y la lujuria en un impresentable afán de denigrar y vituperar a la mujer ${ }^{54}$.

Pero hecha esta advertencia de orden semántico, nada más refrescante que abordar el difícil equilibrio entre lo que representan los conceptos de trabajo autónomo y decente de la mujer. Porque sin duda la autonomía es valor social que da mucho temor y genera incertidumbres, a un nivel parecido al de la constitución de una empresa. El trabajo autónomo es de naturaleza personal y entraña riesgos que no siempre uno se aventura a correr. Sobre todo en unos niveles de aptitud, decencia y respeto sin apoyos reales y eficaces, más allá de cuatro rasgos decorativos de aliento institucional, sistemáticamente contestado (cuando no neutralizado) por intereses económicos basados en el lucro desmedido y en una feroz competencia, más de simpatías y oportunidades que de méritos o interés general ${ }^{55}$.

Todo empieza con la aportación de algunas cifras con que iniciar la disertación: parece ser que sin estadísticas no cabe fundar argumentos. Y no olvidemos que muy a menudo más que una decisión personal (la de establecerse de forma autónoma) suele mostrar-

${ }^{52}$ El Diccionario Latino-Español Nuevo Valbuena (en su 6a edición del año 1846) entronca el vocablo con femineus (citado en la obra del poeta Ovidio, siglo I a. C., autor de obra poética entre la que destaca Ars Amandi) que como adjetivo referido a los tres géneros (neutro incluido) hace referencia a lo femenil, femenino o relativo a las mujeres.

${ }^{53}$ Sin duda, estas digresiones son fruto de algunas páginas del internet sabelotodo y sin escrúpulo alguno que vienen a retratarse en su propia miseria intelectual. La paradoja consiste en comprobar que tanto femen como femur no se corresponden ni con femenino ni con lo masculino: ambos son vocablos neutros.

${ }^{54} \mathrm{Sin}$ duda esta postura solo puede ser fruto de mentes delirantes que obtienen como resultado el verse reflejados en su propio desvarío.

${ }^{55}$ Se habla del trabajo autónomo como nicho de trabajo, pero muy a menudo se transforma más que en un vivero de posibilidades laborales en un lugar muy distinto más próximo a su concepto opuesto: un verdadero mortuorio donde sin remedio caen muchos emprendedores osados. 
se como una alternativa al desempleo ${ }^{56}$ y a la crisis; eso sí, además ofrece mayor libertad aunque sea a costa de un deterioro en el salario y en las expectativas. Todo muy claro y directo. Y muy convincente.

Por eso debe reivindicarse el trabajo autónomo como propósito decente ${ }^{57}$. Nada que antes no se hubiese abordado aunque dicho con nuevas palabras, forjadas a menudo en los esfuerzos de traducción que llegan desde la cultura anglosajona. En todo caso se trata de identificar la decencia con el desempeño de la actividad laboral en condiciones justas y con la debida protección a las mujeres. Y para lograr ese objetivo una premisa debe quedar asegurada: la mayor indecencia es no tener trabajo. No olvidemos que la raíz latina de la palabra decente proviene del verbo decet, decuit, parecer o estar bien, ser conveniente o decoroso, con etimología en el griego deijo, mostrar. En resumidas cuentas, masculla con ironía y pensamiento atrevido nuestra oyente ${ }^{58}$, que lo autónomo es terreno proceloso, un campo de minas, plagado de riesgos e incertidumbre por el que mejor no caminar sin el preceptivo manual de instrucciones y siempre de la mano de la diosa fortuna.

Por supuesto que los déficits en materia de conciliación quedan retratados y ponen a la vista todas sus vergüenzas. Porque, claro, rige la autonomía de la voluntad aunque el Derecho Social no termine de llegar. Sí, hay que reconocer que existe una ley especial que regula esta materia y que los derechos fundamentales quedan garantizados... ipero poco más! Y lo mismo hay que sostener de los derechos a la seguridad y a la salud. En esto podemos recrear toda la literatura que se quiera para decir y desdecir de forma hiperbólica cuanto nos venga en gana. Y aproximar los mundos, antagónicos o complementarios, de lo propio y lo asalariado, de lo público y lo privado. Y de la mujer al hombre y viceversa. Siempre amagando pero sin centrar el tiro. Eso sí, se quiere pero a medias porque falta la voluntad de llevarlo a cabo. Así de simple.

Y para muestra, un botón. En este punto la ponente se refiere a la protección social. Y por razón etimológica se pone muy seria: el régimen especial de los trabajadores autónomos es un sistema rígido y flexible a la vez. Me gusta esta dicotomía, piensa para sí. Y todo ello -prosigue la relatora- en un contexto de tránsito desde el trabajo informal al formal evitando situaciones de marginalidad y no contributividad. Esto último nuestra protagonista no lo ha entendido muy bien, pero no le importa porque -piensa- lo importante es la comprensión de contexto ${ }^{59}$. La misma sensación tiene cuando se expone que el concepto

\footnotetext{
${ }^{56}$ Generalmente puede asociarse a la deficiente protección por desempleo en la mujer las peores condiciones previas de trabajo y la discriminación que sufren en el acceso al mismo. El profesor Suárez Corujo ilustra con nitidez este hecho dando cuenta de los ejes que explican la peor posición de las mujeres en el sistema de protección por desempleo. Distingue, de una parte, entre el sesgo estructural que representa el mejor tratamiento de las carreras típicas masculinizadas; y de otra, como segundo eje, el agotamiento del sistema mediante el paro de larga duración que sufre una mayor proporción de mujeres y que atribuye al fracaso de las políticas activas de empleo. Un tercer eje vendría dado por los recortes de carácter coyuntural que, de forma subrepticia, les perjudica en mayor medida mediante una reforma invisible y neutra en términos de género. Y todo para deducir, como resultado de su confluencia, unas negras perspectivas que terminarán agravando la vulnerabilidad de las mujeres ante el desempleo (La protección por desempleo desde la perspectiva de género, Universidad Carlos III de Madrid, 17 de octubre de 2016. p. 10).

${ }^{57}$ Los pilares del Objetivo 8, esto es, promover el crecimiento económico inclusivo y sostenible, el empleo y el trabajo decente para todos, son los que tradicionalmente han venido sustentando los derechos básicos de los trabajadores.

${ }^{58}$ En este punto cabría aventurar una penosa consecuencia: el trabajo autónomo se concibe como un subgrupo o modalidad del trabajo flexible que determina un desigual reparto de la riqueza.

${ }^{59}$ En el apartado V de su ensayo El lenguaje jurídico actual (Editorial Aranzadi, Cizur Menor 2007) Luis María Ca-
} 
de habitualidad en el autónomo flexible debe ser objeto de nuevo planteamiento. Pero esta vez cuando se habla de la reforma del sistema del autónomo en su conjunto, de sus características y peculiaridades, ninguna duda alberga de que reina un contexto de trabajo, además de autónomo, indecoroso ${ }^{60}$.

Este sombrío panorama se confirma cuando se aborda como opción la cuestión del trabajo digital y el realizado mediante nuevas plataformas en un mercado laboral que ofrece pocas oportunidades de empleo. Eso se dice porque es pura realidad. Y ante tan fatal descripción no cabe sino expresar -ahora se mastica en la sala un halo de frialdad- mucho derrotismo y resignación. Que la economía colaborativa es una oportunidad no deja de tener chispa; mejor, es un grito desesperado ante el incendio que puede producir para mantener la supervivencia a cambio de comprometer la mismísima dignidad del trabajo.

En efecto, es manifestación de trabajo no decente en la mujer; como el que se revela por fraude en las cooperativas ${ }^{61}$ y mediante el uso desviado de la tarifa plana en los autónomos ${ }^{62}$. Y como por ensalmo una inesperada lágrima empieza a recorrer su mejilla izquierda. Y piensa con estremecimiento que alguien está manejando los hilos del destino para disponer la escasez y los recursos marginales como alternativa al trabajo decente ${ }^{63}$.

\section{Epílogo y propuestas}

La sesión ha terminado. Antes de partir al espacio que el destino le tiene reservado, cierra los ojos, se hunde plácidamente en el confort del asiento y hace balance de la maravillosa experiencia académica que acaba de disfrutar, todo un regalo inesperado que le gustaría conservar. Y como madre y mujer sueña:

\subsection{El trabajo no decente debe ser erradicado mediante un nuevo marco normativo en que prevalezcan los derechos fundamentales de mujeres y hombres sin quebranto en su ejercicio.}

7.2. La tarea de alcanzar ese escenario es responsabilidad de todos. La dignidad en el trabajo no se consigue declarándolo -como si se tratase de un título sin contenido alguno- sino poniendo los medios necesarios en su garantía y tutela.

\footnotetext{
zorla condensa el sentido del estudio al señalar como objetivo la sintonía que la principal herramienta del jurista debe guardar con las circunstancias sociales preponderantes pero con mantenimiento de su propia entidad y alcance (p.73).

${ }^{60}$ La sola facultad de optar por el quantum de la cotización debiera desaparecer, pues las rentas altas terminan escapando al régimen privado de prestaciones.

${ }^{61}$ Las llamadas empresas sociales han podido ser buen ejemplo y modelo de adaptación a los cambios en los difíciles momentos de crisis económica. También la aparición de plataformas de mujeres como Somos Autónomas y la Asociación de Mujeres en las Artes Visuales Contemporáneas demuestran la importancia del fenómeno desde una inequívoca perspectiva de género.

${ }^{62}$ Sin duda en la reformulación de la tarifa plana anida un propósito de alentar el desarrollo de proyectos de autoempleo como expresión de economía regular.

${ }^{63}$ Existe en la actualidad un llamado Plan Director por un Trabajo Digno para el periodo 2018-2020 nacido al amparo del diálogo político y social, que mediante la actividad que contempla (a desarrollar por la Inspección de Trabajo y Seguridad Social) viene a reforzar el Plan de Acción para la Implementación de la Agenda 2030 aprobado por el Consejo de Ministros el día 29 de junio de 2018.
} 
7.3. La igualdad de género es principio irrenunciable que en su dinámica nace de una misma y única identidad sustancial y se proyecta marcando inevitables y enriquecedoras diferencias.

7.4. El trabajo de la mujer tiene un enorme potencial tanto a nivel individual como asociativo, pero necesariamente deben removerse los obstáculos que impiden su desarrollo tanto en el ámbito familiar como profesional.

7.5. Dejemos de hablar del trabajo decente como si fuera una rareza de laboratorio, un fármaco experimental contenido en un tubo de ensayo.

Despierta a tiempo de comprobar que las luces se han apagado y los asistentes se han ido. Ella sigue en el mismo sitio, sorprendida, anclada todavía a sus emociones. Impulsada por un viento favorable y cálido, casi levitando, acierta a dar unos cuantos pasos, inseguros y desganados. Abandona el auditorio y se dirige a casa: unos cartones sucios a poca distancia de allí.

Anochecía en una calle cualquiera.

\section{Bibliografía citada}

AA.VV. El futuro del trabajo que queremos, Ministerio de Empleo y Seguridad Social, Madrid 2017.

ALAMEDA CASTILLO, María Teresa, Trabajo autónomo decente de la mujer, en Blázquez Agudo, Eva María (Dir.), Los ODs como punto de partida para el fomento de la calidad del empleo femenino, Editorial Dykinson, Madrid 2018.

ÁLVAREZ DE MIRANDA, Pedro. El género y la lengua, Turner Minor, 2018.

ARAGÓN GÓMEZ, Cristina, Propuestas de reforma legislativa, en materia de Seguridad Social para hacer emerger el trabajo autónomo irregular, Documentación Laboral, número 107, 2016.

BLÁZQUEZ AGUDO, Eva María (Dir.). Los ODs como punto de partida para el fomento de la calidad del empleo femenino. Editorial Dykinson, Madrid 2018.

CAZORLA PRIETO, Luis María. El lenguaje jurídico actual, Editorial Aranzadi, Cizur Menor (Navarra), 2007.

DICCIONARIO LATINO-ESPAÑOL, el Nuevo Valbuena (6ª edición) Paris, en la Librería de Don Vicente Salvá, 1846.

FERNÁNDEZ LÓPEZ, María Fernanda. La dimensión laboral de la violencia de género (comentario a la L.O. 1/2004, de 28 de diciembre), Editorial Bomarzo, Albacete, 2005.

GARCÍA DE ENTERRÍA, Enrique. Prólogo al estudio de Luis María Cazorla Prieto El lenguaje jurídico actual, Editorial Aranzadi, Cizur Menor (Navarra), 2007.

GORELLI HERNÁNDEZ, Juan. Trabajo y necesidades familiares: la reducción y adaptación del tiempo de trabajo. Iustel. RGSS, vol. 48, 2018.

HERRAIZ MARTÍN, María Sol. La gestión del tiempo de trabajo en el siglo XXI. Editorial Laborum. Murcia, 2014. 
LÓPEZ INSUA, Beatriz. El principio de igualdad de género en el Derecho Social del Trabajo, Editorial Laborum, Murcia, 2017.

LLEDÓ IÑIGO, Enrique. Dar razón. Conversaciones. KRK Ediciones, 2017.

MORENO SOLANA, Amanda. La prevención de risgos laborales de los trabajadores especialmente sensibles. Tirant lo Blanch, Valencia, 2010.

NIETO ROJAS, Patricia. Dimensión de género en el tratamiento convencional de la seguridad y salud laboral, en Blázquez Agudo, E.M., Informe sobre salud laboral desde la perspectiva de género, Instituto de Estudios de Género. Uc3m, 2017.

ORDINE, Nuccio. La utilidad de lo inútil (20ª ed.), Acantilado, Barcelona 2018.

QUINTERO LIMA, María Gema. La protección a la familia desde una perspectiva de género, en Blázquez Agudo, Eva María. Prestaciones de Seguridad Social y Género. OISS, 2017.

SUÁREZ CORUJO, Borja. La protección por desempleo desde la perspectiva de género, Universidad Carlos III de Madrid, 17 de octubre de 2016.

URRUTIA GÓMEZ, Jaime. La verdad convenida, Literatura y Comunicación, Editorial Biblioteca Nueva, Madrid, 1997. 